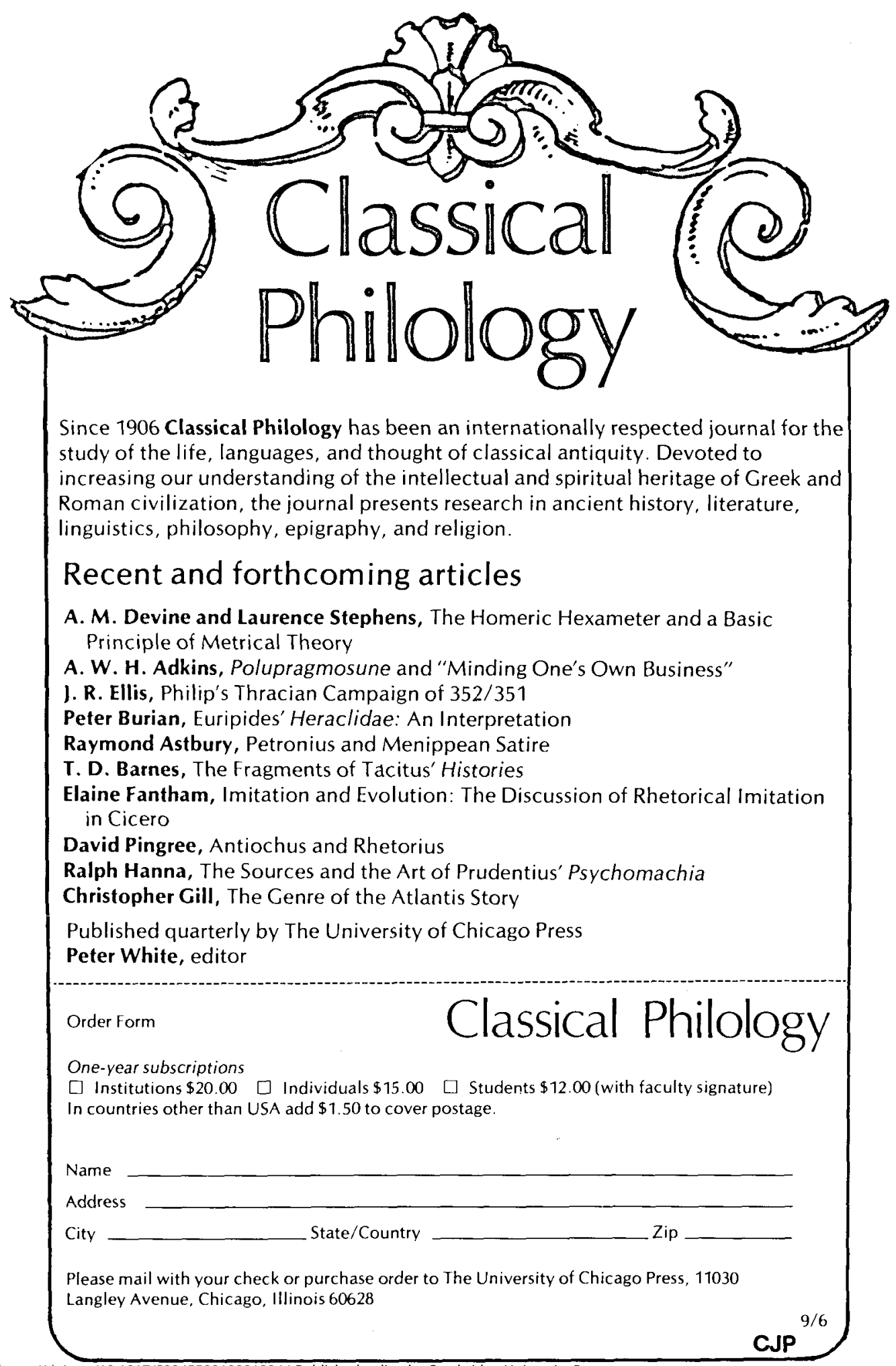




\section{RESEARCH IN PHENOMENOLOGY}

Published annually by Humanities Press Editor: John Sallis

Research in Phenomenology is dedicated both to encouraging original, creative phenomenological research and to furthering the interpretive and critical study of the writings of major phenomenological philosophers. It also provides in-depth reviews of the most important current work in phenomenology.

Advisory and Editorial Committees: Paul Ricoeur, Otto Pöggeler, Werner Marx, Edward Ballard, Calvin Schrag, William Earle, Joseph Kockelmans, Hans Jonas, William Richardson, André Schuwer, Richard Zaner, John Scanlon, Edward Gelblum, Lester Embree.

Subscription rate: Research in Phenomenology is published annually by Humanities Press each winter. Effective with volume 6, subscription rates are $\$ 10.00$ per year for libraries and $\$ 7.50$ for individuals. Single issues of volumes 1 through 5 are still available at $\$ 6.50$ each.

All correspondence concerning manuscripts should be sent to the Editor, Department of Philosophy, Duquesne University, Pittsburgh, Pa. 15219.

All correspondence concerning subscriptions should be sent to Humanities Press, Inc., Atlantic Highlands, N.J. 07716.

\section{The Journal of Philosophy}

Subscriptions at $\$ 10.00 /$ year; $\$ 7.00$ to students $\$ 16.00$ to libraries and institutions

The trustees and editors of the Fournal of Philosophy announce a change in scheduling: as of January 1977, the Fournal will be published monthly. There will be no change in the number of pages of copy published, since the monthly issues will be equivalent to the earlier double issues, and special issues will be published when needed. No change in price is anticipated.

Complete back volumes and all separate issues of the Journal are available, back to its founding January 7, 1904. Also, a cumulative Fifty-year Index, 1904-1953 and Tenyear. Supplement 1954-1963.

720 PHILOSOPHY HALL, COLUMBIA UNIVERSITY, NYC 10027 